\title{
Total Synthesis, Stereochemical Reassignment and Absolute Configuration of Chlorofusin
}

\author{
Sang Yeul Lee, Ryan C. Clark, and Dale L. Boger \\ Department of Chemistry and the Skaggs Institute for Chemical Biology, The Scripps Research \\ Institute, 10550 North Torrey Pines Road, La Jolla, California 92037
}

Chlorofusin (1, Figure 1A) was isolated from the fungal strain Microdochium caespitosum and found to disrupt the MDM2-p53 interaction by binding to the N-terminal domain of MDM2. ${ }^{1}$ As such, chlorofusin represents an exciting lead for antineoplastic intervention that acts by a rare disruption of a protein-protein interaction. ${ }^{2}$ On the basis of spectroscopic and degradation studies, the structure was proposed to be composed of a densely functionalized chromophore linked through the terminal amine of ornithine to a nine residue cyclic peptide. ${ }^{1}$ Although the studies permitted the identification of the cyclic peptide structure and connectivity, the two asparagine residues were only established to have opposite stereochemistries ( $\mathrm{L}$ and $\mathrm{D}$ ) and their respective assignments were not possible. Previously, we reported the synthesis of the two cyclic peptide diastereomers bearing either the $\mathrm{L}_{\mathrm{L}}-\mathrm{Asn} 3 / \mathrm{D}-\mathrm{Asn} 4$ or $\mathrm{D}-\mathrm{Asn} 3 / \mathrm{L}$-Asn 4 stereochemistry and were able to correlate the former with the spectroscopic properties of the natural product. ${ }^{3}$

Similarly, the spectroscopic studies conducted by Williams provided an assigned relative stereochemistry for the chromophore, but did not permit an assignment of its absolute stereochemistry (Figure 1B). The relative stereochemistry was assigned using gradient 1D NOE studies albeit entailing a long range C4-Me/C8-H NOE observed only at very extended mixing times (500 ms).

Prompted by the recent disclosure of Yao that purports to have prepared chlorofusin, ${ }^{4}$ herein we report our independent reassignment of the chromophore relative stereochemistry that is still, but less obviously, consistent with the experimental NOEs reported by Williams, and an assignment of its absolute configuration that is opposite that disclosed by Yao. A total synthesis of this revised chlorofusin structure provided material displaying spectroscopic properties indistinguishable from that reported for the natural product confirming the new chromophore structural assignment and establishing the accuracy of our earlier ${ }_{\mathrm{L}}-\mathrm{Asn} 3 / \mathrm{D}-\mathrm{Asn} 4$ cyclic peptide assignment.

Since the absolute configuration of the chromophore was unknown, the route pursued in our first generation synthesis permitted access to both enantiomeric series and to all possible diastereomers, albeit developed to access the Williams assigned diastereomer depicted in Figure 1B. The azaphilone 2 was prepared following established protocols 5 and was chromatographically resolved (Daicel CHIRALCEL $®$ OD column, $2 \times 25 \mathrm{~cm}, 20 \% \mathrm{EtOH}-$ hexanes, $7 \mathrm{~mL} / \mathrm{min}, t_{\mathrm{R}}: 22.2 \mathrm{~min}(S)$-2, $\left.25.0 \mathrm{~min}(R)-2\right)$ into its enantiomers. Their absolute configurations were assigned based on the diagnostic sign of the longest wavelength (350-370 $\mathrm{nm})$ Cotton effect in their CD spectra ${ }^{6 \mathrm{a}}$ which, for such simple azaphilones, empirically has been shown to also correlate with the similarly diagnostic sign of their optical rotation. ${ }^{6} \mathrm{~b}$ The $\mathrm{N}^{\delta}$-amine of ornithine in dipeptide 3 , constituting the ${ }_{\mathrm{L}}-\mathrm{Orn}-\mathrm{L}-\mathrm{Thr}$ segment of the cyclic peptide,

boger@ scripps.edu. 
was condensed with azaphilones $(R)-\mathbf{2}$ or $(S)-\mathbf{2}$ to provide $\mathbf{4}$ and $\mathbf{5}$ (Scheme 1). Subjection of each to a single-step oxidative spiroketalization $\left(\mathrm{I}_{2}, \mathrm{AgNO}_{3}, \mathrm{H}_{2} \mathrm{O}-\mathrm{DMSO}\right)$ of the $\mathrm{C} 8$-C9 double bond provided all four diastereomers of the two enantiomeric series. Although space precludes a discussion of the development of this protocol, it is initiated by reversible iodonium ion formation and subsequent iodoetherification with $N, O$-ketal formation followed by $\operatorname{Ag}(\mathrm{I})$ assisted displacement of the iodide by $\mathrm{H}_{2} \mathrm{O}-\mathrm{DMSO}$ providing 6-13 directly. The major products, in which the $\mathrm{C} 8$ and $\mathrm{C} 9$ oxygen substituents are syn possessing the $\mathrm{C} 8 / \mathrm{C} 9$ stereochemistry found in the Williams assignment, represent those that formally arise from a trans iodoetherification reaction followed by $\mathrm{S}_{\mathrm{N}} 2$ displacement of the iodide by water. Analogous to and extending unambiguous stereochemical assignments (x-ray and interconversion studies) made first with model benzylamine and $n$-butylamine azaphilone adducts (Supporting Information), the structures of all 8 diastereomers were fully assigned using COSY, HMQC, HMBC, and ROESY NMR. The two syn and two anti diastereomers in each enantiomeric series are readily distinguishable by diagnostic ${ }^{1} \mathrm{H}$ NMR $(\mathrm{C} 10-\mathrm{H}, \mathrm{C} 12-\mathrm{H}$ and $\mathrm{C} 8-\mathrm{OH})$ and ${ }^{13} \mathrm{C}$ NMR $\left(\mathrm{C} 1, \mathrm{C} 2,{ }^{7} \mathrm{C} 6,{ }^{7} \mathrm{C} 10\right.$ and $\left.\mathrm{C} 12\right)$ chemical shifts, and the two anti diastereomers within each enantiomeric series are most readily distinguished by diagnostic $\mathrm{C} 8$ $\mathrm{H}, \mathrm{C} 13-\mathrm{H}$ and $\mathrm{C} 8-\mathrm{OH}{ }^{1} \mathrm{H}$ NMR and $\mathrm{C} 7$ and $\mathrm{C} 13{ }^{13} \mathrm{C}$ NMR chemical shifts. Supporting the assignments were $\mathrm{N}, \mathrm{O}$-ketal equilibration studies which relate syn/anti diastereomer pairs.

Out of this set of 8 diastereomers, the $(4 R, 8 S, 9 R)$-diastereomer 9 provided a near perfect match with the spectroscopic properties reported for the chlorofusin chromophore, whereas the $4 S$, $8 R, 9 S$ )-diastereomer 13 (chromophore enantiomer) proved readily distinguishable by both the ${ }^{1} \mathrm{H}$ NMR chemical shift and multiplicity of the ornithine $\mathrm{CH}_{2}{ }^{\delta}$ adjacent to the chromophore $(\delta 3.45, \mathrm{~m}, 2 \mathrm{H}$ for $\mathbf{9}$ vs $\delta 3.41$ and 3.52 , two $\mathrm{m}, 1 \mathrm{H}$ each for $\mathbf{1 3}$; chlorofusin $=\delta 3.42$, t, $2 \mathrm{H}$ ). This final multiplicity distinction allowed the absolute stereochemical assignment for the chromophore.

Accordingly, the $(4 R, 8 S, 9 R)$-diastereomer 9 was incorporated into a total synthesis of chlorofusin. Fmoc deprotection (piperidine, $\mathrm{CH}_{2} \mathrm{Cl}_{2}$-DMF, $40 \mathrm{~min}$ ) and coupling of the free amine 14 with the carboxylic acid of heptapeptide 15 cleanly provided 16 (EDCI, HOAt, $\mathrm{NaHCO}_{3}$, DMF, 0 to $\left.23{ }^{\circ} \mathrm{C}, 24 \mathrm{~h}, 55 \%\right)$. Simultaneous benzyl ester deprotection and $\mathrm{Cbz}$ removal $\left(\mathrm{H}_{2}, \mathrm{Pd} / \mathrm{C}\right.$, THF-DMF, $\left.4 \mathrm{~h}\right)$ provided the corresponding amino acid $\mathbf{1 7}$ which was cyclized upon treatment with EDCI-HOAt $\left(\mathrm{NaHCO}_{3}\right.$, DMF, 0 to $\left.23{ }^{\circ} \mathrm{C}, 40 \mathrm{~h}, 60 \%\right)$ to provide material with spectroscopic properties indistinguishable from that reported for chlorofusin. In addition to natural chlorofusin, the $(4 R, 8 R, 9 R)$-diastereomer proposed by Williams as well as the $(4 R, 8 S, 9 S)$ and $(4 R, 8 R, 9 S)$-diastereomers of chlorofusin were also prepared by this route from 6-8 and the anticipated non-correlation of their spectroscopic properties with that reported for the natural product provided further support for the new structural assignment.

This $(4 R, 8 S, 9 R)$-diastereomer $(\mathbf{1})$ is clearly distinguishable from the diastereomer reported by Yao who correctly reassigns the chromophore relative stereochemistry, but which possesses the wrong the absolute stereochemistry. His $(4 S, 8 R, 9 S)$-diastereomer (the chromophore enantiomer), even with his adjusted chemical shifts, exhibited the diagnostic ornithine $\mathrm{CH}_{2} \delta$ signal as two multiplets of $1 \mathrm{H}$ each ( $\delta 3.42$ and 3.50) analogous to $\mathbf{1 3}$ (vs $\delta 3.42, \mathrm{t}, 2 \mathrm{H}$ for natural ${ }^{1}$ and synthetic chlorofusin) making it readily distinguishable from the data reported for the natural product. ${ }^{8}$

\section{Supplementary Material}

Refer to Web version on PubMed Central for supplementary material. 


\section{Acknowledgment}

We gratefully acknowledge the financial support of the National Institutes of Health (CA41101) and the Skaggs Institute for Chemical Biology. We especially thank Dr. S. S. Pfeiffer for initial studies on the chromophore synthesis and Dr. S. S. Pfeiffer and Dr. P. Desai for the original studies on the chlorofusin cyclic peptide. ${ }^{3}$ SYL and RCC are Skaggs Fellows.

\section{References}

(1) (a). Duncan SJ, Grueschow S, Williams DH, McNicholas C, Purewal R, Hajek M, Gerlitz M, Martin S, Wrigley SK, Moore M. J. Am. Chem. Soc 2001;123:554-560. [PubMed: 11456567] (b) Duncan SJ, Cooper MA, Williams DH. Chem. Commun 2003:316-317.

(2). Boger DL, Desharnais J, Capps K. Angew. Chem., Intl. Ed 2003;42:4138-4176.

(3) (a). Desai P, Pfeiffer SS, Boger DL. Org. Lett 2003;5:5047-5050. [PubMed: 14682761]For additional preparations of this cyclic peptide, see: (b) Malkinson JP, Zloh M, Kadom M, Errington R, Smith PJ, Searcey M. Org. Lett 2003;5:5051-5054. [PubMed: 14682762] (c) Tomonori M, Miyagi M, Suzuki K, Shibasaki M, Saikawa Y, Nakata M. Heterocycles 2007;72:275-291.

(4). Qian W-J, Wei W-G, Zhang Y-X, Yao Z-J. J. Am. Chem. Soc 2007;129:6400-6401. [PubMed: 17472388]

(5). Chong R, King RR, Whalley WB. Chem. Commun 1969:1512-1513.For additional studies on azaphilones related to the chlorofusin chromophore, see:Zhu J, Grigoriadis NP, Lee JP, Porco JA Jr. J. Am. Chem. Soc 2005;127:9342-9343. [PubMed: 15984841]Wei W-G, Qian W-J, Zhang YX, Yao Z-J. Tetrahedron Lett 2006;47:4171-4174.

(6) (a). Steyn PS, Vleggaar R. J. Chem. Soc., Perkin Trans. 1 1976:204-206. (b) Whalley WB, Ferguson G, Marsh WC, Restivo RJ. J. Chem. Soc., Perkin Trans. 1 1976:1366-1369.

(7). These two assignments ( $\delta 115.2$ for $\mathrm{C} 2,101.3$ for $\mathrm{C} 6$ as reported by Williams), may be switched ( $\delta 101.3$ for $\mathrm{C} 2,115.2$ for $\mathrm{C} 6$ ). This tentative reassignment is under continued investigation.

(8). Subsequent to the web disclosure of ref. ${ }^{4}$ as well as following the completion of our work, we reexamined a sample of authentic chlorofusin provided by Dr. Stephen Wrigley (2003, but aged and of unknown quality) that failed to provide a discernable ${ }^{1} \mathrm{H}$ NMR spectrum at that time. With an intimate knowledge of the chromatographic and physical properties of such compounds in hand, the processing of the remaining material $(<1 \mathrm{mg})$ provided a sample that exhibited a CD spectrum indistinguishable (sign and magnitude) from synthetic 1 confirming our absolute configuration assignment and an ${ }^{1} \mathrm{H}$ NMR spectrum of sufficient quality to confirm that it represents the authentic natural product (see Supporting Information). 


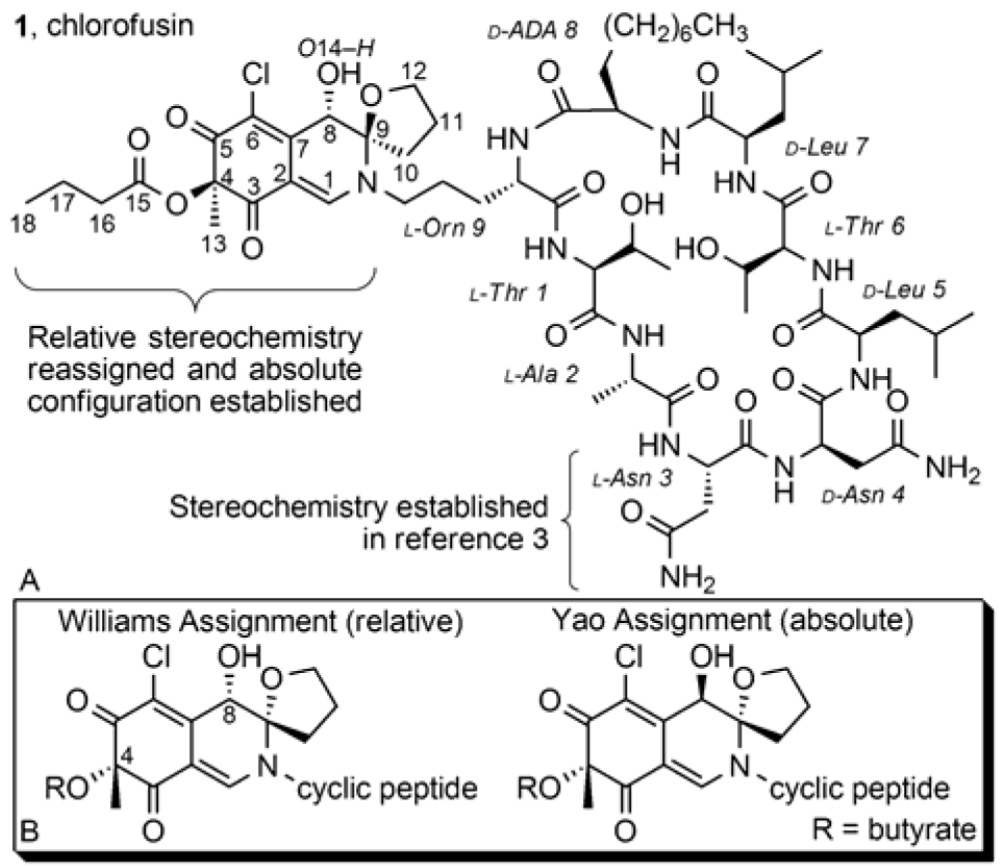

Figure 1.

A. Chlorofusin. B. Previous chromophore assignments. 
Fmoc-L-Orn-L-Thr-OBn, 3<smiles>[R10][C@@]1(C)C(=O)C2=COC(CCCO)=CC2=C(Cl)C1=O</smiles><smiles>[Y20][Y20](=N)CC[Ge]</smiles><smiles>[R20][C@@]1(O)C(=O)C2=CNC(CCCO)=CC2=C(Cl)C1=O</smiles>
$\sqrt{\mathrm{H}_{2} \mathrm{O}-\mathrm{DMSO}}$
Fmoc-L-Orn-L-Thr-OBn, 3

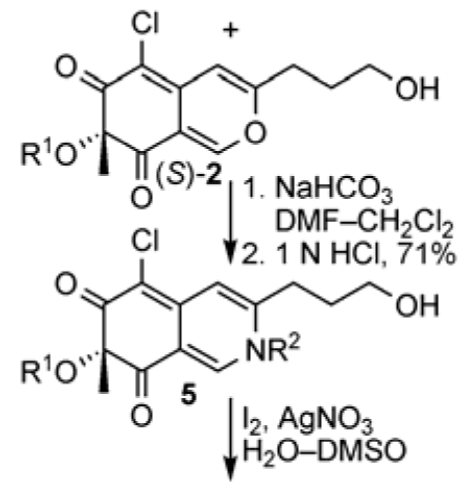

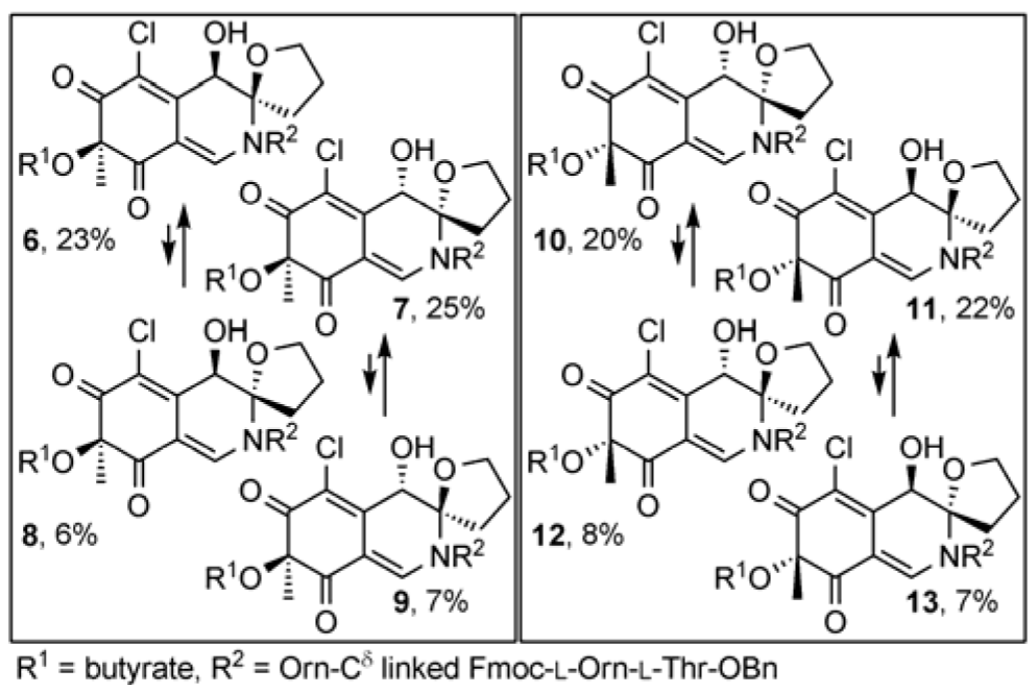

Scheme 1. 


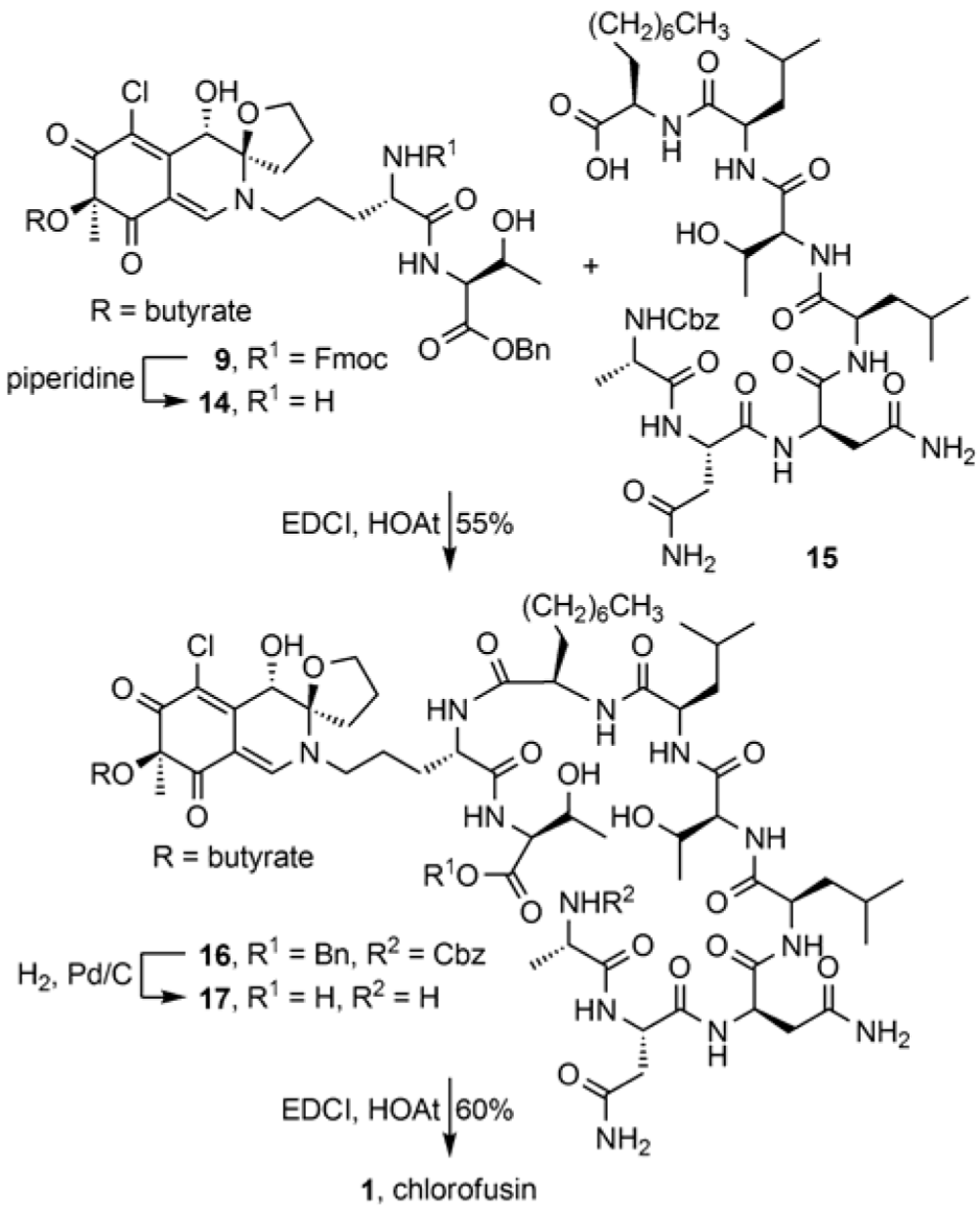

Scheme 2.

Synthesis of chlorofusin 